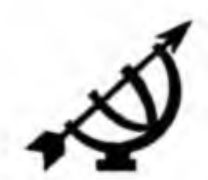

\title{
Ouerbegeleiding in die nuwe Suid-Afrika: voorvereiste vir beter matriek-uitslae?
}

Driekie Hay

Strategiese diens vir Hoëronderwys en -navorsing

Universiteit van die Vrystaat

BLOEMFONTEIN

E-pos: hayr@rs.uovs.ac.za

\author{
Kobus Smit \\ Opvoedkunde Departement \\ Vista Universiteit \\ BLOEMFONTEIN \\ E-pos: smit-j@blenny.vista.ac za
}

\begin{abstract}
Parent support programmes in the new South Africa: prerequisite for better matric results?
\end{abstract}

The 1997 matriculation results with a failure rate of 52,9\%, once again caused great concern country-wide (Jansen, 1998:56). With the exception of Mpumalanga, the pass rate of all the provinces has decreased (Duffy, 1998:10). Five years after apartheid and with a new education dispensation being applied, the expected outcomes in terms of better matriculation results hove not yet been realised (Haasbroek, 1998:12-13). The effect of this failure rate is extensive. During the 1993/1994 tax year matric failures cost South Africa R2,38 milliard. This is 13\% of the total education budget (Die Volksblad, 1995:12-30). The extent of the 1997 failures has not yet been calculated in financial terms.

In educational ranks there is as yet uncertainty regarding the possible manner in which this problem might be addressed. Is the solution to be found in more schools, in lower teacher-pupil ratios, or in other resources? A possible intervention strategy might probably be that of parent accompaniment. The home should indeed be the place where the young child should feel safe enough so that his/her potential might develop to the full. If the parent, for whatsoever reason, does not meet this responsibility, the total personal and intellectual development of the child is impeded.

\section{Inleiding}

Die matriek-uitslae van 1997 , met 'n druipsyfer van $52,9 \%$, het opnuut skokgolwe die land ingestuur (Jansen, 1998:56). Al die provinsies, behalwe Mpumalanga, se slaagsyfer het gedaal (Duffy, 1998:1) en vier jaar na apartheid en met 'n nuwe onderwysbedeling, het die verwagte uitkomste in terme van beter matriekresultate nog nie gerealiseer nie (Haasbroek, 1998:12-13). Die effek wat hierdie druipsyfer het, is omvangryk. Gedurende die 1993/1994 belastingjaar het matriekdruipelinge Suid-Afrika R2,38 miljard gekos - 'n bedrag wat soveel as 
Ouerbegelelding In die nuwe Suld-Afrika: voonerelste vir beter matrlek-ultslae?

$13 \%$ van die totale onderwysbegroting was, (Die Volksblad, 1995-12-30 - kyk Anon., 1995). Die omvang van 1997 se druipsyfer is nog nie in finansiële terme bereken nie.

Onderwysgeledere is nog onseker oor die moontlike invalshoek van waaruit die probleem gehanteer behoort te word. Lê die oplossing in meer skole, in laer onderwyserleerling-ratio's of in ander hulpbronne? Een moontlike intervensiestrategie blyk waarskynlik die van ouerbegeleiding te wees. Die huis behoort tog immers dié plek te wees waar die jong kind geborge behoort te voel om sy volle potensiaal te verwesenlik. Indien die ouer, om watter rede ook al, nie hierdie verantwoordelikheid nakom nie, belemmer dit die kind in sy/haar totale persoons- en intellektuele ontwikkeling.

\section{Teoretiese vertrekpunt}

Binne die nuwe Suid-Afrika met sy multikulturele reënboognasie word kinderopvoeding, insluitende die rol van die ouer, vanuit verskillende vertrekpunte beoefen. Een so 'n vertrekpunt is die Christelike waarheidsbeskouing waarbinne opvoeding beoefen word. Binne hierdie lewensbeskouing word die opvoeding van die kind in sy totaliteit as 'n Godgegewe opdrag aan die ouer gegee. Vir die Christen-waarheidsbeskouer vind die verstandelike ontwikkeling van die kind doelgerig en planmatig plaas (Schoeman, 1996:161-163)

Die Christelike lewensbeskouing word bevraagteken deur onder andere linkse opvoedkundiges. So word die waardes en norme tiperend van reformatoriese opvoedkunde dikwels vereenselwig met apartheid. Dit is waarskynlik so omdat die Christelike perspektief van opvoeding verwar word met Christelik-nasionale Onderwys. Higgs (1993:21) wys daarop dat onderrig binne Christelik-nasionale onderwys voltrek moet word tussen onderwysers as opvoeders en kinders van dieselfde rassegroep, nasie, en kultuur. Die gevolg is dat teenstanders en kritici van hierdie benadering die mening uitspreek dat die Christelike wetenskapsbeoefening nie 'n plek binne die nuwe Suid-Afrikaanse konteks het nie. Vir teenstanders is so 'n opvoedkundige stelsel nie in ooreenstemming met die grondwet nie. In die Suid-Afrikaanse konteks behoort egter gepoog te word om ander sienwyses en filosofiese vertrekpunte te respekteer - die grondwet vereis dit.

Die post-modernistiese perspektief op opvoedkunde bevraagteken die waarde van formele kennis en opvoeding en glo dat populêre kennis en informele opvoeding relevant is (Higgs, 1996:141; Schoeman, 1996:118, 120). Binne 'n post-modernistiese wêreldbeskouing word kennis deur massamedia en gevorderde kommunikasie (soos die Internet) beskikbaar gestel. Die bestaan van sosiale, ekonomiese, en omgewingsprobleme word erken as deel van ons wêreld en daar word aanvaar dat perspektiewe en grense gedurig verander en skuif. 
Eweneens is die Suid-Afrikaanse samelewing deurspek met neo-Marxistlese grondslae (Higgs, 1996:124; Schoeman, 1996:169). Neo-Marxiste beskou die mens as 'n selfbeskikkende en selfregulerende entiteit en sy eie wetgewer. Die pedagogiese steun van ouers aan hul kinders binne die neo-Marxistiese model word afgeskaal. So glo die neo-Marxis dat daar nie in die kind se natuurlike groeiproses, natuurlike eksplorasie, selfontdekking en selfekspressie ingegryp moet word nie. Neo-Marxiste glo in 'n anti-outoritêre opvoedingsbenadering waarbinne die gesag van die ouer bevraagteken word.

Die liberale humanistiese sienswyse verwys na die beginsel van liberale outonomie en fokus op die individu se humanistiese waarde. Daar word van die kind verwag om sy eie bestemming te bepaal. Dit laat die ouer onseker oor watter rol hy/sy in die kind se vorming behoort te speel. Ouers waak daarteen dat hulle nie die kind se waardigheid, sy reg tot uniekheid, sy vryheid en sy moontlikhede inperk nie (Schoeman, 1996:45).

Die aanvaarding van 'n New-Age sienswyse (Olsen, 1997:20) is dat alles die mens geoorloof is; dat alle gelowe, kulture en lewensfilosofieë aanvaarbaar is ten einde 'n reënboognasie te wees.

Dit blyk derhalwe nodig te wees dat 'n emstige besinning moet kom oor watter rol ouerbegeleiding binne die nuwe Suid-Afrikaanse konteks kan vervul. Met reg kan gesoek word na antwoorde op vrae soos:

- Watter rol kan ouerbegeleiding in die heropbou en ontwikkeling van SuidAfrikaanse samelewings speel?

- Watter impak kan ouerbegeleiding op beter matriekuitslae hê?

\section{Doel van die artikel}

In hierdie artikel word betoog dat die eerste paar jare in 'n kind se lewe die belangrikste is en ' $n$ invloed het op latere leer, ontwikkeling en prestasie (selfs ook matriekprestasie) (Engelbrecht, 1994:1; Short, 1992:240; Le Roux, 1994: 153; Van den Berg \& Vergnani, 1986:12). Die outeurs van hierdie artikel is van mening dat die meeste matriekdruipelinge afkomstig is uit gesinne waar hulle reeds vanaf geboorte aan veral opvoedkundige verwaarlosing blootgestel is.

\section{Gevolge van opvoedkundige verwaarlosing}

Opvoedkundige verwaarlosing verwys na die tekort of gebrek aan stimulerende ervarings in die kind se grootword. Ofskoon hierdie kind nie noodwendig met 'n lae intellektuele vermoë gebore word nie, is dit die ontoereikende omgewing waarin hy grootword wat veroorsaak dat hy nie sy volle potensiaal kan bereik nie. Hierdie opvoedkundige verwaarlosing het implikasies vir die kind se persoons-, intellektuele en taalontwikkeling. 
Persoonlikheidskenmerke van so ' $\mathrm{n}$ kind is volgens Kok (1970:21-29), Pretorius (1990:210-212) en Meintjes (1990:92) die volgende: 'n swak selfbeeld - hulle het gewoonlik min selfvertroue wat deur druiping en mislukking vererger word; gebrekkige motivering as gevolg van swak opvoedingsbemoeienisse; angs ten opsigte van die skool; min deursettingsvermoë en gebrekkige volharding; 'n gebrek aan inskiklikheid; swak sosiale inskakeling; min selfvertroue en gebrekkige selfhandhawing. Die aanwesigheid van hierdie eienskappe doem die matrikulant tot mislukking.

Die opvoedkundig verwaarloosde kind begin volgens Deutsch (aangehaal in Meintjes 1990:104) op so 'n lae kognitiewe niveau dat "... initial failures are almost inevitable, and the school experiences become negatively rather than positively reinforced". Bender en Bender (1979:7) noem dat, ten opsigte van intellektuele ontwikkeling nie net tussen $60 \%$ en $70 \%$ van kinders met intelligensiekwosiënte tussen 70 en 80 uit opvoedkundig verwaarloosde huisgesinne kom nie, maar dat dit ook dié kinders is wat in spesiale onderwys geakkommodeer word. Biesheuvel (1943:80-81) maak reeds in 1943 die aanname dat milieugeremdheid ' $n$ kind se potensiële intelligensiekwosiënt drasties kan laat daal. Ook Claassen en Schepers (1990:294) wys op die positiewe korrelasie tussen die intelligensie van skoolgaande kinders en hul sosioekonomiese status.

Die vernaamste kenmerke van die intellektueel verwaarloosde kind se intellektuele funksionering sluit volgens Meintjes (1990:109) die volgende in: perseptuele tekorte te wyte aan 'n ongeoefendheid om doeltreffend aandag te gee; gebrekkige kreatiwiteit; gebrekkige algemene kennis; visuele en ouditiewe persepsie wat minder skerp genuanseerd is.

Intellektuele denkvaardighede wat nodig is om op skool te presteer, ontwikkel volgens Zaki (1983:80) nie voldoende by die intellektueel verwaarloosde kind nie. So ' $n$ kind sukkel om byvoorbeeld die verloop en gevolge van 'n situasie te volg en om die omvang van sake te snap.

Ten opsigte van kognitiewe ontwikkeling is die groot agterstand in veral die abstrakte dimensie van verbale funksionering opvallend (Zaki, 1983:80). Taalontwikkeling is ' $n$ belangrike aspek hiervan. Die onvoldoende taalontwikkeling van hierdie kinders is ' $n$ uiters belangrike aspek - juis te meer omdat kinders uit histories benadeelde gemeenskappe dikwels van vroeg af nie meer in hul moedertaal onderrig word nie (Lemmer, 1996:331).

Redes wat deur Roucek (aangehaal in Meintjes, 1990:131) aangevoer word vir hierdie ontoereikende taalontwikkeling is die gebrekkige vokale stimulering tydens die kleinkinderjare en die skaarsheid van gespreksvoering met volwassenes. Kriegler (1990:418) sonder die kommunikasiewyse en -styl van milieugeremde ouers uit as 'n moontlike rede vir die taalgeremdheid aangesien 
milieugeremde ouers nie "inligting-verskaffers" of "vraag-beantwoorders" is nie. Hierdeur word hul kinders se denkprosesse nie ontwikkel nie en brei die kind se kennis nie uit nie.

Hierdie taalagterstand manifesteer homself veral in 'n lae verbale intellektuele funksionering (Pretorius, 1986:59), wat die kind se algemene ontwikkelingsvlak negatief beinvloed (Meintjes, 1990:134). Dumaret (1985:563) en Lemmer (1996:335) verklaar dat milieufaktore 'n groter invloed op verbale as op nieverbale tellings by die samestelling van totale intelligensie uitoefen, en dat " "... social class differences are greater for verbal than non-verbal scores". Hierdie vertraagde en gestremde taalontwikkeling lei dus tot 'n algeheel geïnhibeerde intellektuele ontwikkeling (Zaki, 1983:80; Sternberg \& Grigorenko, 1997:483).

Die opvoedkundige stand van dié samelewingsgroepe waarbinne heropbou en ontwikkeling moet plaasvind, is nie na wense nie. Terselfdertyd bied dit 'n groot uitdaging om met kreatiewe opvoedkundige oplossings vorendag te kom. Dit blyk tog asof een van die moontlike oplossingsinvalhoeke dié van ouerbegeleiding kan wees. ' $n$ Belangrike voorbehoud is egter dat ouers bemagtig moet word om reeds vanaf kinders se geboortes met waardevolle insette te begin - om te wag vir graad nul of graad 1 is nie gewens nie. Teen die tyd dat hierdie kind matriek bereik, het hy reeds soveel mislukking ervaar dat sy kans om te slaag, skraal is.

\section{Die behoefte aan ouerbegeleiding binne histories- benadeelde gemeenskappe}

Uit bogenoemde bespreking is dit duidelik dat kinders en ouers woonagtig in samelewingstrukture/gemeenskappe waar ernstige heropbou en ontwikkeling gedoen moet word, dringende begeleiding nodig het.

Vanweë armoede en die ouers se gebrekkige ervaring kan sulke ouers nie hul kind se intellektuele wording bevorder nie (Meintjes, 1990:13; Van der Ross, 1992:5). Kinderverwaarlosing, groot gesinne en ontoereikende maatskaplike dienste in hierdie woonbuurtes is dikwels aan die orde van die dag (Pretorius, 1986:48; Du Toit, 1992:24). Hierdie gesinne is dikwels vasgevang in ' $n$ armoedespiraal wat vir geslagte in stand gehou word. Volgens Van der Ross (1986:18-19) gee hierdie armoedespiraal aanleiding tot swak/onvoldoende onderwys, wat lei tot swak skoolprestasie, swak loopbaanvooruitsigte, ontoereikende behuising, en die totstandkoming van 'n gesin wat weereens in armoede gebore is. Daar bestaan dan ook 'n duidelike verband tussen armoede en die opvoedkundige kwalifikasies van hierdie gesinne.

Gebrekkige skoolervaring bring mee dat ouers min belangstelling in hul kinders se onderwys en opvoeding toon (Le Roux, 1994:74). Kotzé (1984:79) beweer dat die opvoedkundig verwaarloosde ouers negatief teenoor die skool se 
gesagsposisie is. Thirion (1989:388) is van mening dat hierdie ouers glo dat die skool primêr vir hul kinders se opvoeding verantwoordelik is. Snyman (1990:19) beskou hierdie gebrek aan belangstelling as 'n manifestasie van gebrekkige vaardighede en kennis om hul kinders te help. Dit laat tereg die vraag ontstaan of die kern van swak matriekuitslae nie onder andere verband hou met die onbetrokkenheid van hierdie ouers nie.

Ouers in so 'n gesin beskik nie oor die kennis en vaardighede om hul kinders se denkvaardighede te stimuleer nie en is self nie ' $n$ voorbeeld vir kennisverwerwing nie (Meintjes, 1990:109). Hulle is byvoorbeeld ook nie in staat om geleenthede te skep om voorwerpe van verskillende grootte en voorkoms aan die kind te verduidelik nie. Dit lei daartoe dat die kind later, wanneer hy dit in 'n skoolsituasie nodig het, nie kan onderskei of eksploreer nie (Meintjes, 1990: 108). Die afwesigheid van volwassenes wat fokus bring op objekte, gebeure en idees in die kind se sosiale omgewing, is die eerste fase van latere mislukking op skool (Feuerstein, 1987:xiv; Van den Heuvel, 1986:141).

Die matrikulant vanuit 'n opvoedkundig verwaarloosde omgewing, het dus 'n agterstand wat veral in sy/haar matriekuitslae sal reflekteer. Pogings sal dus aangewend word om te verseker dat genoemde matrikulante se huislike omstandighede groter opvoedkundige ondersteuning bied.

Behoorlike voorskoolse intervensie behoort 'n wesenlike verskil in die akademiese prestasie van matrikulante te maak. In die verlede was voorskoolse intervensiestrategieë meestal onbekostigbaar en ontoeganklik vir 'n groot deel van die Suid-Afrikaanse voorskoolse bevolking. So het die milieubegunstigde voorskoolse kind in die apartheidsbedeling die meeste geld ontvang, terwyl die kind met die grootste opvoedkundige agterstand, R38 per jaar ontvang het. Biersteker (1993:15) wys daarop dat $69 \%$ van 1990 se totale voorskoolse onderwysbegroting aan blanke kinders bestee is. Sy beweer ook dat van die totale onderwysbegroting van R580 miljoen in 1992, slegs $2 \%$ aan voorskoolse onderwyssorg bestee is. Hierdie ongelyke besteding kom ook na vore in terme van staatsondersteuning vir die opleiding van personeel betrokke by voorskoolse onderwyssorg.

Aangesien voorskoolse intervensiestrategieë nie vir histories benadeelde kinders beskore is nie, moet na alternatiewe intervensiestrategieë gesoek word. Ouerbegeleiding is 'n sterk moontlikheid.

\section{Ouerbegeleiding}

Die ontwikkelingsgeskiedenis van ouerbegeleiding op makro-opvoedkundige vlak in Suid-Afrika is volgens Ferreira (1991:10-11) onbekend, veral aangesien ouerbegeleidingsaksies tot dusver nie op 'n nasionale en gekoördineerde wyse plaasgevind het nie. Laasgenoemde outeur spreek die mening uit dat 
ouerbegeleiding in die verlede hoofsaaklik toegespits was op die blanke bevolking, wat meebring dat ander bevolkingsgroepe met hul eiesoortige opvoedings- en ontwikkelingsproblematiek se behoefte aan ouerbegeleidingsprogramme om dringende navorsing en besinning vra (Ferreira, 1991:10-11).

Vermaak (1981:22) beskou die waarde van ouerbegeleiding soos volg: “... om die problematiese opvoedingsituasie noukeurig te peil en geleide verandering en beïnvloeding, gerig op die opheffing van die gesin se opvoedingsnood, te bewerkstellig" (Vermaak, 1981:22). Hierdie definisie blyk in die besonder van toepassing te wees op milieu-benadeelde gesinne waar juis gepoog word om die gesin deur middel van ouerbegeleiding op te hef. Ouerbegeleiding kan verder daarin slaag om deur daadwerklike steun, raadgewing, vorming, leiding en selfs onderwysing, die ouer in staat te stel om sy kind suksesvol tot volwassenheid te begelei (Du Toit aangehaal in Janeke, 1989:104)

Ouerbegeleidingsprogramme kan die volgende opvoedkundige uitkomste of winste tot gevolg hê (Ferreira, 1991:23-24; vergelyk ook Ferreira, 1987:11-12; Jansen, 1993:37):

- Die voorkoming van allerlei probleme, insluitende leerprobleme, gedragsprobleme en ontwikkelingsprobleme.

- Die opvoeding van ouers om kennis en inligting aangaande hulle kinders se totale ontwikkelingsverloop oor te dra.

- Die bewusmaking van ouers se sluimerende opvoedingsvaardighede.

- Die begeleiding van ouers tot die aanvaarding van verantwoordelikheid vir die kind se opvoeding, leeraktiwiteite en gedrag.

- Die toespitsing van ouers se aandag op hul opvoedingsopgawe en -problematiek

- Die verskaffing van inligting aan die ouer.

- Die skoling van die ouer in opvoedingsvaardighede.

- Die verlening van emosionele steungewing.

- Hulpverlening wat voorligting en raadgewing insluit.

- Kompensering vir reeds bestaande probleme soos die leer- en taalprobleme van milieu-benadeelde kinders.

Bogenoemde uitkomste bring die ouer in voeling met sy kind se sosiale, emosionele en intellektuele behoeftes. Daar bestaan verskillende metodes van 
ouerbegeleiding wat aangewend kan word. Sommige van hierdie metodes kan ook gekombineer word.

\subsection{Modi van ouerbegeleiding}

Verskillende modi kan gebruik word om ouerbegeleiding op 'n georganiseerde wyse te laat plaasvind. Ferreira (1991:20) verwys na massa-onderwysmodi (radio, televisie, tydskrifte en koerante) sowel as groepmodi (ouerbegeleidingsgroepe) en individuele modi (tuisbesoeke) wat vir dié doel gebruik kan word. Hierdie modi lewer 'n bydrae om ouers as opvoeders te vorm en toe te rus om hul opvoedingstaak effektief en na behore te volvoer. Myers (1992:122-131) onderskei benewens genoemde modi ook nog volwasse onderrig, geletterdheid en die rol van sibbe. Tabel 1 verskaf inligting oor elk van hierdie wyses.

\section{Tabel 1: Wyses van ouerondersteuning en -begeleiding}

\begin{tabular}{|l|l|l|}
\hline Wyse & Fokus & Doelwit \\
\hline Tuisbesoeke & $\begin{array}{l}\text { Ouers en ander } \\
\text { gesinslede }\end{array}$ & $\begin{array}{l}\text { Verskaffing van inligting en kennis } \\
\text { oor opvoedkundige en ont- } \\
\text { wikkelingsaangeleenthede van die } \\
\text { kind. }\end{array}$ \\
\hline Volwasse-onderrig & Ouers & $\begin{array}{l}\text { Geletterdheid, geleentheid om } \\
\text { skoolloopbaan te voltooi; } \\
\text { verskaffing van inligting oor vroeë } \\
\text { kinderopvoeding. }\end{array}$ \\
\hline Media & Ouers & $\begin{array}{l}\text { Inligtingverskaffing deur radio, } \\
\text { televisie en geskrewe handleidings. }\end{array}$ \\
\hline "Peer tutoring" \\
(deur sibbe) & Ouer kinders & $\begin{array}{l}\text { Verskaf inligting oor kinder- } \\
\text { opvoeding en versorging om te } \\
\text { verseker dat hulle goeie ouers sal } \\
\text { word. }\end{array}$ \\
\hline
\end{tabular}

(Saamgestel uit Myers, 1992:122-131.)

\subsection{Koste-effektiwiteit van ouerbegeleidingsprogramme}

Ouerbegeleidingsprogramme is 'n koste-effektiewe intervensiestrategie wat geensins as ' $n$ minderwaardige metode van intervensie beskou moet word nie. ' $n$ Vergelyking van koste verbonde aan verskillende metodes van voorskoolse intervensie wat deur Short (1992:235) getref word, dui daarop dat ouerbegeleiding R375 per kind kos, terwyl dit vir die regering R6 008 per jaar per 
kind in 'n graadnul-klas kos. Die huis bied inderdaad 'n effektiewe leeromgewing vir die kind en vorm die basis waarop die skool kan voortbou.

\subsection{Buitelandse ouerbegeleidingsprogramme}

In die buiteland bestaan 'n verskeidenheid ouerbegeleidingsprogramme (McCormick \& Hickson, 1996:55) vir milieu-benadeelde gesinne (bv. Head Start, Home Start, High Scope Ypsilanti en Even Start in die VSA, The Mother and Child Home Programme en West Riding Home Visiting Programme in Engeland en Hippy in Israel). Die waarde van die bestaande buitelandse programme vir toepassing in Suid-Afrika verdien ondersoek. Die vernaamste beginsels waarop sommige van die programme fokus, kan soos volg saamgevat word:

- Fokus word op die verbetering van die verbale interaksie tussen moeder en kind geplaas.

- Ouers word bewus gemaak dat hulle 'n belangrike rol kan speel in hul kind se totale ontwikkeling.

- Tuisbesoeke word deur opgeleide personeel reeds vanaf geboorte gedoen.

- Ouers ontvang 'n gedetailleerde werkprogram met gespesifiseerde leseenhede.

- Finansiële steun word vanaf die regering ontvang.

- Geletterdheidsprogramme vir ouers gaan dikwels gepaard met die programme.

- Die ouer en sy kind moet so vroeg moontlik na die kind se geboorte ingeskakel word by die program.

Dit is egter nodig om ook na enkele Suid-Afrikaanse voorbeelde te verwys.

In Suid-Afrika berig Short (1992:266-267) en Biersteker (1995:1-4) oor 'n verskeidenheid programme wat deur die Early Learning Resource Unit (ELRU) in Athlone, Kaapstad, ontwikkel is, en wat op ouers gerig is. ELRU fokus op die volgende vorme van ouerbegeleiding:

- Ouerbewusmakingsprogramme - om ouers bewus te maak van hul opvoedkundige taak. Ouers word deur middel van twaalf gespreksgeleenthede en demonstrasies oor kinderontwikkeling begelei en wenke vir stimulerende aktiwiteite word gegee (Biersteker, 1995:1). 
- Tuis- en gemeenskapsgebaseerde opvoedkundige programme wat direk daarop gemik is om ouers en gemeenskappe by die opvoeding van hul jong kinders te betrek en hulle daarin te ondersteun (Short, 1992:267).

- Tuisbesoekprogramme help die ouer of substituut om 'n verskeidenheid opvoedkundige aktiwiteite tuis te skep. As voorbeeld word verwys na die Home Early Learning Programme wat deur ELRU ontwikkel is vir versorgers van kinders tussen die ouderdom van ses maande en drie jaar. Tuisbesoekers besoek die ouer weekliks oor 'n tydperk van een of twee jaar en moedig die ouer aan om tuis 'n stimulerende omgewing te skep. 'n Netwerk van ouers wat van tyd tot tyd ontmoet om mekaar te ondersteun, word deur die tuisbesoeker georganiseer (Biersteker, 1995:2).

- Oueropleidingsprogramme behels dat opleiers verantwoordelik is vir werkswinkels of groepsbesprekings oor voorskoolse opvoeding (Short, 1992: 267).

- Die ouer-kindgroepprogram (Parent-Child Group Programme) fokus op ouers met kinders tussen die ouderdom van twee en ses jaar. Ouers word deur middel van 'n weeklikse twee-uurlange sessie opgelei om sekere aktiwiteite tuis met hul kinders te doen. Tydens hierdie sessies kry ouers geleentheid om boeke en speelgoed te ruil (Biersteker, 1995:3).

- Hay (1997) het deur middel van aksienavorsing 'n ouerbegeleidingsprogram ontwikkel wat primêr fokus op die ontwikkeling van die verbale intelligensie van kinders in milieugeremde gemeenskappe.

\section{Gevolgtrekking en aanbevelings}

Aangesien die moontlikhede van ouerbegeleiding as waardevolle intervensiestrategie nie ten volle in Suid-Afrika ontgin word nie, behoort dit op nasionale vlak aandag te geniet. As voorbeeld kan verwys word na die HIPPY (Israel) en Home Start (VSA) programme wat deur regerings gekoördineer en finansier word. Die implementering van sodanige programme kan weer aan ouers hul regmatige plek in die samelewing gee - en sodoende kan hulle hul primêre taak ten opsigte van hul kinders se opvoeding nakom. Dit behoort ook waardevolle insette te lewer om die orde en beheer in milieu-benadeelde gemeenskappe te hervestig.

Die aanbeveling van sodanige programme fasiliteer ook werkskepping, wat 'n prioriteit vir heropbou en -ontwikkeling is. So kan 'n projekleier vir 'n spesifieke area aangestel word. Hierdie projekleier moet dan ouerbegeleidingsprogramme in die spesifieke area inisieer en vestig. Hierdie area word in vier verdeel, met 'n programleier wat deur die projekleier opgelei word vir elke area Programleiers lei tuisbesoekers op wat ouers besoek, die ouerbegeleidings- 
program verduidelik, en met behulp van demonstrasies en handleidings die ouers ondersteun asook deeglike evaluering van vordering doen. Tuisbesoekers moet weer verslag doen aan programleiers in die spesifieke areas en laasgenoemde aan die projekleier. Die program(me) behoort ook van tyd tot tyd gemonitor te word en die nodige aanpassings gemaak te word. Geletterdheidsonderrig behoort deel te wees van ouerbegeleidingsprogramme.

\section{Samevatting}

Uit bogenoemde bespreking is dit duidelik dat kinderopvoeding in milieugeremde gemeenskappe nie na wense is nie. Ouers in sulke gemeenskappe beskik nie dikwels oor die nodige kennis en ervaring om waardevolle, normatiewe insette ten opsigte van hulle kinders se totale ontwikkeling te lewer nie. Die verwarring van ander nie-Christelike waardesisteme laat twyfel by die ouers ontstaan en belemmer hulle om hul primêre taak na te kom. Hierdie situasie durf nie gelate aanvaar te word nie: die Christen-opvoedkundige moet in sy wetenskapsbeoefening hierdie geleentheid aangryp om deur weldeurdagte, wetenskaplike navorsing en insette normatiewe rigting te gee aan milieugeremde gemeenskappe, veral wat die opvoeding van ons kinders betref.

\section{Bibliografie}

ADAMS, B.W. 1996. A consideration of key factors contributing to underachievement in South African Schools. (In Engelbrecth et al Perspectives on learning difficulties: International concerns and South African realities. Cape Town : Van Schaik. p. 312-323.)

ANON 1995. Druipelinge jaag Suid-Afrika miljarde uit die sak. Die Volksblad:12, Des 30

BENDER, M. \& BENDER R.K. 1979. Disadvantaged preschool children - a source book for teachers. Baltimore : Brookes Publishing Co.

BIERSTEKER, L. 1993. Early childhood educare in South Africa - A situation analysis. South Africa : UNICEF

BIERSTEKER, L 1995. Inligtingstuk oor ouer- en gemeenskapsprogramme soos deur die "Early Learning Resource Unit". Kaapstad : ELRU

BIESHEUVEL, S 1943 African intelligence. Johannesburg : South African Institute for Race Relations.

CLAASSEN, N.C.W. \& SCHEPERS, J M 1990. Groepverskille in akademiese intelligensie verklaar op grond van verskille in sosio-ekonomiese status. Suid-Afrikaanse Tydskrif vir Sielkunde, 20(4):294-301.

DIE VOLKSBLAD $k y k$ ANON 1995

DUMARET, A. 1985. IQ, scholastic performance and behaviour of sibs raised in contrasting environments. Journal of Child Psychology and Psychiatry, 26(4):553-580

DUFFY, A. 1998. Bloody battle starts over schools. (Internet). Johannesburg. Electronic Mail \& Guardian. Beskikbaar by:http//wn.apc.org/wmail/issues/900109/ NEWS3 htm. (Besoek 01 September 1998 )

DU TOIT, ME. 1992. Milieugestremd: is daar hoop? South African Administration. Prisma Year, 7 (5):24-44

ENGELBRECHT, C.S. 1994 Die gesin is die kind se eerste skool. Kurr-i-komm, 20 (2):1-4

FERREIRA, G.V. 1987. Ouerbegeleiding op makro-opvoedkundige vlak Navorsingsverslag Johannesburg : Randse Afrikaanse Universiteit. 
FERREIRA, G.V 1991 Die operasionalisering van makrostrategieë vir ouerbegeleiding deur nie-formele en informele onderwys in 'n multikulturele samelewing. Navorsingsverslag. Johannesburg : Harman.

FEUERSTEIN, R. 1987. Instrumental enrichment - An intervention programme for cognitive modifiability Baltimore : University Park Press

HAASBROEK, C. 1998. Successful schools: What makes the difference? In Focus Forum, (6): 12-15.

HAY, H R. 1997. 'n Ouerbegeleidingsprogram vir die verbale intellektuele stimulering van voorskoolse milieugeremde kinders. Pretoria : Vista Universiteit. (Ph.D.-proefskrif.)

HIGGS, P. 1993. Philosophy of Education in a democratic South Africa. Educare, 22(1 \& 2): 19-31.

HIGGS, P. 1996. Metatheories in philosophy of education. Johannesburg : Heinemann

JANEKE, C.F 1989 Die buite-egtelike kind se selfaktualisering. Pretoria : Unisa. (D.Edproefskrif)

JANSEN J D. 1998. Why education policies fail. Indicator South Africa, 15(1):56-58

JANSEN, C A 1993 Ouerbegeleiding in 'n komtemporêre samelewing. Pretoria : Unisa (D Ed-proefskrif.)

KOK, J.C. 1970. 'n Pedagogiese beoordeling van die waarde-oriëntasie by milieugestremde kinders. Port Elizabeth : Universiteit van Port Elizabeth. (D.Ed-proefskrif.)

KOTZÉ, E. 1984. Die sosiale lewe van die kind. (In Sonnekus M.C.H., red. Opvoeding en opvoedingsprobleme tussen ouer en kind. Pretoria : HAUM Opvoedkundige Uitgewers. p. 75-89.)

KRIEGLER, S.M. 1990 Informele onderwys: 'n sleutel tot die onderwyskrisis in SuidAfrika? Suid-Afrikaanse Tydskrif vir Opvoedkunde, 10 (5):417-421.

LEMMER, E M. 1996. Selected linguistic realities in South African schools: Problems and prospects (In Engelbrecht et al. Perspectives on learning difficulties; International concerns and South African realities. Cape Town : Van Schaik. p. 324-339.)

LE ROUX, J. 1994 The black child in crisis. Volume 2. Pretoria : Van Schaik.

McCORMICK, K. \& HICKSON, J 1996 Early intervention; A global perspective. (In Engelbrecht et al. Perspectives on learning difficulties; International concerns and South African realities. Cape Town. Van Schaik. p. 55-70.)

MEINTJES, B J J. 1990. Pedagogiese, psigologiese en sosiale kenmerke van die milieugestremde gesin. Pretoria : Universiteit van Pretoria. (Ph.D.-proefskrif.)

MYERS, R 1992. The twelve who survive: Strengthening programmes of early childhood development in the Third World. London : Routledge.

OLSEN, KE. 1997. Outcomes based education: an experiment in social engineering? Kranskop : Khanya Press.

PRETORIUS, J.W.M 1986 Kompensatoriese onderwys. Ongepubliseerde navorsingsverslag Pretoria : Universiteit van Pretoria

PRETORIUS, J.W.M. 1990 Opvoeding, samelewing, jeug: 'n sosiopedagogiese leerboek Pretoria : Van Schaik.

SCHOEMAN, P G. 1996. Ideology, culture and education Bloemfontein : Tekskor

SHORT, A. 1992 Early childhood education. (In McGregor, R. \& McGregor, A., eds Education alternatives. Cape Town : Juta p. 231-249.)

SNYMAN, A. 1990. Milieugestremde kinders: Ouers benodig leiding. Onderwysbulletin, 29(1) 19

STERNBERG, R.J. \& GRIGORENKO, E. 1997. Intelligence, heredity and environment. New York : Cambridge University Press.

THIRION, G.J 1989. Verband tussen die onderrig-leersituasie en die sosio-ekonomiese leefwêreld van leerlinge in ontwikkelende samelewings. Suid-Afrikaanse Tydskrif vir Opvoedkunde, 9(2):386-391 
VAN DEN BERG, O \& VERGNANI, T. 1986. Providing services for preschool children in South Africa. Bellville : University of the Western Cape.

VAN DEN HEUVEL, D 1986. Children at risk: A resource and planning guide. Madison Wisconsin Department of Public Instruction.

VAN DER ROSS, R. 1992. Communication problems of deprived children. The Child Care Worker, 10(3):5-7.

VAN DER ROSS, R. 1986. Providing services for preschool children in South Africa. (In Van den Berg, O. \& Vergnani, T., eds. Bellville : University of the Western Cape p. 1627.)

VERMAAK, M.C.G. 1981. Die ontwerp en evaluering van 'n funksionele ouerbegeleidingsmodel vir die ouer van die wordingsgeremde adolessent. Pretoria : Unisa. (M.Ed-verhandeling.)

ZAKI, M 1983. The problem of the culturally deprived child. School Psychology International, 4:79-84. 